\title{
Colombia y el dilema clásico del apoyo cinematográfico
}

\section{Colombia and the classic dilema of cinematographic support}

\section{Óscar Arias, Enrique Uribe y Toby Miller \\ Universidad del Norte, Universidad Externado de Colombia y University of California, Riverside}

Fecha de recepción: 30 de octubre de 2018

Fecha de aprobación: 3 de diciembre de 2018

DOI: http://dx.doi.org/10.15304/ricd.2.9.5570

\section{NOTAS BIOGRÁFICAS}

Óscar Arias es profesor catedrático en Universidad del Norte, en Colombia. Comunicador Social y Periodista. Máster en Dirección Cinematográfica por Universidad de Barcelona. Miembro del grupo de Investigación en Comunicación, Cultura y Cambio Social PBX de Universidad del Norte.

Contacto: oscara@uninorte.edu.co

Enrique Uribe es docente investigador en Facultad de Comunicación Social-Periodismo de Universidad Externado de Colombia. Miembro del Grupo Recasens de Investigación en Comunicación. Miembro del comité editorial de las revistas Palabra Clavey Campos.

Contacto: enrique.uribe@uexternado.edu.co

Toby Miller es profesor e investigador en University of California, Riverside; Sir Walter Murdoch Profesor de Estudios en Políticas Culturales, Murdoch University; Profesor Invitado de Escuela de Comunicación Social en Universidad del Norte y Profesor de Industrias Mediáticas y Creativas en Loughborough University London. Presidente de Cultural Studies Association (US).

Contacto: tobym69@icloud.com

\section{Resumen}

El cine ha experimentado un crecimiento considerable en Colombia en los últimos 15 años, particularmente a partir de la Ley del Cine (Ley no 814, 2003) que permitió y promovió el desarrollo de películas colombianas, a la vez que fomentó distintas etapas de creación y distribución audiovisual. No obstante, el incremento en producciones y algunos éxitos de taquilla no significan que el cine nacional haya devenido en una industria sólida, rentable y culturalmente consolidada. Por otra parte, más recientemente, una nueva política cultural, amparada en el interés económico de corto plazo, busca atraer inversión extranjera en el audiovisual a través de ventajas económicas y tributarias enmarcadas en la Ley Location Colombia (Ley no1556, 2012). Está Ley ha sido considerada un éxito el Ministerio de Cultura, aunque sus réditos no se han probado como sostenibles más allá del beneficio temporal en términos de empleo y ocupación hotelera. El desarrollo del cine nacional y la ejecución de estas dos leyes evidencian el cambio de discurso entre la industria cultural y la industria creativa, con un énfasis marcado en el interés económico por encima del beneficio social y cultural. 


\section{Abstract}

Colombian film has experienced considerable growth over the last 15 years. This has been stimulated in part by the Law of Cinema (Law 814, 2003), which promoted the development of Colombian films, at the point of both creation and distribution. However, the increase in production, and the success of some blockbusters, does not mean that national cinema has become a solid, profitable, and culturally resonant industry. More recently, a new cultural policy, based on short-term economic interest, seeks to attract foreign investment in the audiovisual sector through economic and tax advantages framed in the Location Colombia Law (Law 1556, 2012). This Law is considered a success by the Ministry of Culture, although its revenues have not been proven as sustainable beyond the temporary benefit gained from stimuli to employment and hotel occupancy. The overall development of Colombian national cinema, and the experience of these two laws, shows a change in discourse from cultural policy to creative-industries policy, with a marked emphasis on economic interest over social and cultural benefit.

\section{Palabras clave}

Políticas culturales, cine, Colombia, industrias creativas, economía naranja.

\section{Keywords}

Cultural policy, film, Colombia, creative industries, orange economy.

\section{Sumario}

1. Introducción

\subsection{Historia}

2. La industria cinematográfica y el cine nacional

3. Cine colombiano: realidades y desafíos

4. El apoyo de la Ley 814 de 2003

5. Lo bueno, lo malo y lo feo de la Ley 1556

6. Economía Naranja y Duque

7. Conclusiones

\section{Contents}

1. Introduction

\subsection{History}

2. The film industry and national cinema

3. Colombian cinema: realities and challenges

4. The support of Law 814/2003

5. The good, the bad and the ugly of Law 1556

6. Orange Economy and Duque

7. Conclusion 


\section{INTRODUCCIÓN}

Colombian filmmaking is caught in such powerful global riptides that the "nation" can no longer operate as a repository for a set of protective cultural values, and either disappears as the privileged signifier of a putative "national cinema," or is portrayed as little more than a ruse enacted by the predatory local clients of global systems of wealth extraction. (Kantaris, 2017, p. 152) ${ }^{1}$.

El dilema clásico que confronta las políticas cinematográficas, desde su primera formación y a través del mundo, es la relación entre las ideas de desarrollar la cultura contra desarrollar la industria -deseos estéticos contra imperativas comerciales- (Moran, 1996; Miller y Yúdice, 2004).

Muchas veces, ese dilema está expresado en la interacción de dos tipos de recursos. Un tipo está basado en la idea de patrimonio, el otro en acumulación secundaria; uno en la ciudadanía, el otro en el consumo.

Dentro las políticas a favor del desarrollo industrial, hay otra bifurcación. Durante la época de la industrialización de sustitución de importaciones como ruta hacia el desarrollo económico y social, que duró de las décadas 40 hasta las 70, hubo un énfasis en el proteccionismo. Después, en nuestra era de industrialización orientada a la exportación, se privilegia los mercados abiertos, con más oportunidades para Hollywood y menos para los locales.

Es por eso por lo que Colombia tiene muchos incentivos para atraer la producción hollywoodense (Echeverri, 2014), para insertarse en la nueva división internacional del trabajo cultural (Miller, 2018). La orientación actual favorece mercados abiertos para importar películas y rentar la nación como escena internacional -no hay protección cultural en la forma de cuotas, tampoco incentivos exclusivamente locales para profundizar el sector a causa de su capacidad de mostrar lo local a los ciudadanos e invitar a la auto-reflexión-.

No hay mucha literatura académica sobre las políticas cinematográficas colombianas (Villegas y Alarcón, 2017; pero véase Martínez, 2008). Esperamos añadir un poco con este análisis, y explicar aquellas instancias en las cuáles era más un asunto de cuestiones de expresión nacional cultural y menos de mercados abiertos y ganancias financieras.

\subsection{HISTORIA}

No se sabe a ciencia cierta cuándo se filmaron las primeras imágenes en cine de Colombia, pero sí se sabe que las primeras imágenes vistas fueron las proyecciones de los hermanos Di Domenico en la costa caribe, bajo títulos como: Vida, pasión y muerte de nuestro señor Jesucristo (Pathé, Zecca y Nonget, 1905) y El conde de Montecristo (Selig, Boggs y Persons, 1908). Ante el éxito logrado por estas exhibiciones, en 1910 se encargaron nuevas películas a Italia, cuya cinematografía sería la primera influencia internacional (Acosta, Amaya, Alzate, Jaramillo y Zambrano, 2003).

Las primeras tomas producidas en el país corresponden a situaciones o paisajes que podían parecer exóticos y que se realizaron para causar asombro en otras partes del mundo. La Fundación Patrimonio Fílmico en Colombia registra que quedan algunas imágenes de Panamá que fueron exhibidas el 13 de abril de 1897 en Puerto Colón, Panamá, que era entonces parte del territorio colombiano (Ministerio de Cultura, 2015). La desaparición del material fílmico de los inicios de la cinematografía en Colombia, principalmente entre las dos primeras décadas de 1900-1920, es al tiempo un interesante comienzo y un extraño presagio (Acosta, Amaya, Alzate, Jaramillo y Zambrano, 2003). El cine realizado en Colombia será, de este modo, un eterno ir y volver entre surgimiento y descuido.

La primera base estatal para estimular el cine fue la formación de una filial cinematográfica en el Ministerio de Educación en los 30. En 1942 vino la Ley $n^{\circ}$ 9, que ofreció promoción y protección industrial para el sector, garantizando $80 \%$ de capital nacional como inversión en proyectos colombianos. En los 70, el Estado ha introducido la Ley de Sobreprecio, dedicado a mandatar que los teatros ofrecieran cortometrajes nacionales antes de la proyección de largometrajes. En la misma década, el gobierno ha establecido la Compañía de Fomento Cinematográfico (Focine) dentro del Ministerio de Comunicaciones para desarrollar un cine nacional. Focine se cerró en los 90, y hubo algunos años después sin producción de largometrajes colombianos (Martínez, 2008).

A finales del siglo $X X$, fue claro que la industria del cine colombiano era casi inexistente. El cambio a la situación actual tras los primeros 18 años del siglo XXI es evidente. Los desarrollos en tecnología, nuevos directores, nuevas narrativas y nuevos festivales, a lo largo y ancho del territorio (Proimágenes, 2017), han 
marcado un nuevo periodo dentro del desarrollo de la industria cinematográfica ${ }^{2}$ en Colombia. Entre 2002 y 2016 , se pasó de 7 largometrajes anuales a 47 (con un pico de 57, en 2015) que gozan de la denominación de producto nacional (Dirección de Cinematografía, 2017, p. 78) y entre 2009 y 2016 casi se duplican el número de salas de cine, aumentando en $67 \%$ el número de sillas, llegando a 180.905 . Fuera de esto, a 2016 se habían realizado 22 producciones internacionales amparadas por la Ley $n^{\circ} 15.56$ (2012) cuyo éxito ha sido definido a partir de haber traído amplia inversión extranjera y creado "10.394 empleos a nivel nacional [...] entre los que se encuentra personal técnico y artístico, actores principales y secundarios, figuras y extras." (MinCultura, 2016, p. 16).

Desde el consumo de cine, alrededor de 61,44 millones de personas asistieron a salas de cine en 2016, a comparación de 20,67 millones en 2007 (Proimágenes, 2017). El consumo cinematográfico tiende al alza con un crecimiento del $197 \%$ en número de asistentes y $257 \%$ en la taquilla de los últimos diez años. Esto ratifica la demanda de una industria, aunque no necesariamente el consumo de la producción local. En el caso del cine considerado como producción nacional, la asistencia alcanzó los 4,7 millones de personas en 2016 -la cifra más alta hasta la fecha-. Representó un $7,8 \%$ de la asistencia total (Dirección de Cinematografía, 2017, p. 100).

En términos de participación económica y laboral, el audiovisual -que incluye el cine, la televisión y otros servicios como la publicidad- tiene una participación importante entre las industrias culturales y creativas nacionales. Entre 2005 y 2016, estas últimas representan el 1,1\% del valor agregado de la economía nacional, con un crecimiento promedio anual del $5,8 \%$. Entre ellas, la industria audiovisual genera al $42 \%$ del valor agregado (DANE y Observatorio Cultura y Economía, 2017). Además de estos datos, se considera que el total de puestos de trabajo equivalentes a las horas de trabajo mencionadas en las encuestas del sector es de 40.857, en 2016; de los cuales 30.669 corresponden a empleados asalariados (con contratos fijos 0 a término indefinido) y 10.188 a independientes.

Dos elementos de política cultural han sido fundamentales para el desarrollo de la industria cinematográfica en Colombia en el siglo XXI. Por una parte, la Ley $n^{\circ} 814$ (2003), denominada la Ley del Cine o, más recientemente, la Primera Ley del Cine. Es la pieza de legislación "por la cual se dictan normas para el fomento de la actividad cinematográfica en Colombia" como su título de proclamación indica. Esta ley establece el Fondo para el Desarrollo Cinematográfico, que obtiene su financiación a partir de un impuesto aplicado a los ingresos de exhibidores y distribuidores ( $8.5 \%$ de sus ingresos totales) y también a aquellos de los productores (5\% de sus ingresos) y que busca promover el cine nacional. Por otra parte, la Ley $n^{\circ} 1.556$ (2012), denominada Location Colombia o la Segunda Ley del Cine, "por la cual se fomenta el uso del territorio nacional como escenario para el rodaje de obras cinematográficas." que también busca el fomento de la actividad y el desarrollo de la industria cinematográfica, a través de descuentos de impuestos y reembolsos a la inversión en el territorio nacional.

Claramente, la industria del cine nacional no hubiese tenido el gran momento del que goza, si no fuese por esas dos políticas que, aunque tienen un trasfondo diferente, han surgido como estrategias gubernamentales para la promoción de esta industria en una manera comercial, aunque con asistencia estatal; o sea, bienestar corporativo.

\section{LA INDUSTRIA CINEMATOGRÁFICA Y EL CINE NACIONAL}

Ahora bien, esta industria audiovisual, el cine como medio de comunicación masivo, no es solo un eje productivo de elementos de consumo, sino que es una máquina de ideas, signos, símbolos, iconos, y conceptos (Metz, 1990); Hesmondhalgh (2013, pp. 26-33) que plantea que, a diferencia de otras industrias de la producción capitalista, la industria audiovisual -como parte de las industrias culturales- tiene unas características fundamentales que se pueden dividir entre problemas y compensaciones (a dichos problemas). Los problemas incluyen que son negocios de alto riesgo de inversión; que deben ubicarse entre creatividad y éxito comercial, con altos costos de producción, pero bajos costos de reproducción; y que son productos semi-públicos que requieren que se genere artificialmente su escasez. La forma en que se compensa estos problemas incluye que se balanceen las perdidas con amplios portafolios; se permita la concentración e integración de las fases de la industria; se genere escasez artificial a partir de control legal de la distribución; se produzca una clasificación en formatos identificables (por ejemplo, el género); y se incentive una relativa laxitud 
frente al creador simbólico, mientras se impone un control fuerte a la distribución y el mercadeo. Estos problemas y compensaciones son centrales en toda política cultural enfocada al cine.

Los Estados-nación son particularmente relevantse para que se controle, se restrinja o promueva cualquier industria cultural, pues "los actores domésticos continúan determinando amplia-mente las dinámicas de la política mediática y la habilidad de los estados-nación para controlar asuntos fundamentales del gobierno mediático continúan siendo primor-diales para determinan como operan las empresas mediáticas" (Flew \& Waisbord, 2015, p. 633), dado que son los Estados-nación quienes ejercen controles de importación y exportación, de contratación y distribución de recursos, que determinan el acceso audiovisual.

Por estas razones, en la producción cinematográfica se categoriza el mundo aún a partir de las naciones. Los festivales de cine, alrededor del mundo, identifican sus títulos dentro de las categorías de país de origen, etiquetándolos bajo géneros como "Cine Japonés" o "Cine Francés" e incluso como "Cine Nacional Italiano," "Cine del Norte de Irlanda," o "Cine Catalán,", para tan solo mencionar algunos. Este género está concebido, no a partir de características narrativas, sino a partir de formas y orígenes de la producción, y determina de cierto modo un condicionante para su consumo. El análisis contemporáneo del cine nacional, desde la comunicación social, nos muestra las expresiones culturales geográficas de la nación (Hjort \& Mackenzie, 2005). Colombia puede entonces estudiarse y comprenderse como nación a partir de los elementos que estructuran la construcción de su cine nacional y las políticas culturales que se establecen para su desarrollo.

El cine colombiano ha representado distintas etapas de la historia nacional, y sus historias han viajado desde lo local, hacia lo regional y global. Las películas colombianas adolecen de baja exhibición y, a su vez, una distribución regida por grandes empresas que determinan cortos tiempos de exhibición en sala (Proimágenes, 2017), lo cual lleva a que la población colombiana tenga poco acceso a los títulos cinematográficos a lo largo del territorio.

Por ejemplo, un caso de éxito a considerar es el largometraje documental Colombia magia salvaje (Forero y Slee, 2015), cuya taquilla superó los USD 5 millones, con más de 2,7 millones de asistentes a sala, pero que no recibe denominación de producción nacional (Dirección de cinematografía, 2015, p. 40). Este largometraje con- tó con una estrategia que incluía la oportunidad para los consumidores de una cadena de supermercado de reclamar boletos de cine para asistir a las proyecciones de la película. Lo interesante de esto no es solo la estrategia de mercadeo, sino que el director es de nacionalidad inglesa, mostrando paisajes colombianos con la narración del periodista colombiano Julio Sánchez Cristo, como fórmula de construcción del relato (Dinero, 2015). Si este caso demostró que podía existir buena respuesta de la taquilla a una obra documental, no se comprende porque no se ha continuado con este tipo de estrategias para otra producción nacional; estas alianzas podrían convertirse en una forma de mercadeo generando mayor asistencia en salas y así generando fortaleza en el consumo cinematográfico en el país.

Ahora bien, en la actualidad los estudios sobre cine han buscado encontrar respuestas ante los avances tecnológicos, tales como el Video On Demand (VOD), la distribución a través de digital videodiscos (DVDs) (Wasko, 2014), pues llevan a cuestionar la categoría misma de cine o televisión, para privilegiar aquella de audiovisual, por ser esta última más amplia (Uribe, 2016). Este puede parecer un debate meramente académico, por tratarse de la definición conceptual de un medio específico -el cine-, o un lenguaje utilizado por varios medios el audiovisual-. Sin embargo, esta categorización determina el tipo de producto que puede hacerse merecedor del apoyo brindado por las leyes $n^{\circ} 814$ y $n^{\circ} 1.556$ mencionadas anteriormente, así que tiene efectos reales. Un caso sorprendente es el de Narcos (Brancato, Bernard, Miro y Padilha, 2014), pues no obstante ser una serie de televisión distribuida por Netflix, logró conseguir apoyo de la Ley $\mathrm{n}^{\circ} 1.556$ (MinCultura, 2016), destinada supuestamente solo para producciónes cinematográficas. Esta inclusión implica que el producto cinematográfico se deslinda de la idea de exhibición en sala, y por eso, otros beneficiarios de la Ley $n^{\circ} 1556$ (2012) incluyen obras cinematográficas que pueden haber sido exhibidas únicamente en espacios que no incluyan salas de cine, sea televisión, cable, u over-the-top media services (OTTs).

\section{CINE COLOMBIANO: REALIDADES Y DESAFÍOS}

Dentro de la oferta a la que estamos expuestos en la cartelera nacional, existen títulos que claramente reflejan la industria de Hollywood. 
Actualmente, uno de los productos cinematográficos que mayor consumo tiene en el mundo es el largometraje (Thompson \& Bordwell, 2010). Este fue estandarizado, precisamente, por la industria de Hollywood, que a lo largo de la historia del cine ha construido un sistema interconectado, fomentando una hegemonía durante décadas, en la que el público se encuentra inmerso en historias, géneros, estéticas, e ideologías establecidas por los major studios norte-americanos (Benshoff, 2015). Colombia no es ajena a esta prevalencia del cine de Hollywood, pues del Top 20 de películas exhibidas en Colombia en 2016, una sola es de origen nacional, mientras que las otras 19 son producciones cuya clasificación de lugar de origen es Estados Unidos (Dirección de cinematografía, 2017, p. 99).

Contrario a los partes positivos que se dan desde las instituciones nacionales con respecto al avance en nuestro desarrollo en la producción y consumo de cine, debemos tener en cuenta la dimensión desigual del asunto. A 2016, de los 1.102 municipios de Colombia, solo 60 cuentan con salas de cine, con un total de 1.006 salas de cine en el país (Dirección de cinematografía 2017, pp. 41-42). En términos de extensión, esto representa que un $58 \%$ de la población nacional, cerca de 28 millones de personas, tuvieron la oportunidad de encontrar oferta cinematográfica en su lugar de residencia (Dirección de cinemetografía, 2017, p. 7). Aquí vemos ya como el cine se convierte en una experiencia reducida y fundamentalmente urbana, pues Bogotá (275), Cali (91), Medellín (81) y Barranquilla (47) concentran el $49 \%$ de las salas del país (Dirección de cinematografía, 2017, p. 42).

Las películas colombianas han tenido defensores y detractores, pero no se puede dejar de lado que, en la última década, pese a que la asistencia a las películas colombianas ha sido variable el número de asistentes a las salas a consumir productos locales ha aumentado, aunque el porcentaje frente a la asistencia total a cine haya disminuido. Entre 2008 y 2016, el punto más bajo en asistencia fue de 1,2 millones de personas en 2009 y el punto más alto, 4,7 millones en 2016. Pero en términos de relación con la asistencia total, el punto más alto fue en 2008 , con $10,5 \%$ del total de asistencia nacional, al 4,5\% en 2010 y $4,7 \%$ en 2015. Finalmente, de un promedio de 174.848 espectadores por película colombiana en 2008 , hemos bajado a 78.777 en 2014 , recuperándose levemente a 116.871 en 2016 (Dirección de cinematografía, 2017: 29-30). En términos de ingresos por taquilla, la tendencia es proporcional a lo presentado anteriormente, siendo el pico más alto el año 2016, con un total de 35.369 millones de pesos recaudados, y el año de menor ingreso el 2009 con 7.676 millones. A partir del 2014 se observa una tendencia al alza que se ha mantenido hasta 2016 (Dirección de cinematografía, 2017, p. 29).

Estas cifras pueden indicar que el mayor número de películas nacionales diluyen el público dispuesto a verlas, o que solo existen unas pocas películas exitosas, y una gran cantidad de obras que no son disfrutadas por amplios públicos. La diversidad en las propuestas cinematográficas no ha podido generar una confianza en torno a la reputación del cine colombiano. En muchos casos se observan productos que han tenido cierto grado de éxito en la televisión y han migrado a la pantalla grande. Un ejemplo de ello es el personaje de Don Jediondo, quien ha llegado al cine con historias como Muertos de Susto (Carrillo, García y Trompetero, 2007) o Piroberta junto a la Bruja Dioselina, personajes que han ganado cierta relevancia por su éxito en el programa de humor televisivo Sábados Felices, siendo personajes de televisión estrenaron su película en sala con Operación Piroberta (García y Castellanos, 2017). En estos casos, queda de lado la calidad en historias y argumentos, para tratar de reflejar el éxito de la industria televisiva en la industria cinematográfica.

Don Jediondo hace su aparición en la película más taquillera de la historia colombiana, El Coco (García, Toro, Boshell y Pinzón, 2016). Tan solo para mostrar un ejemplo del éxito del paso de la televisión al cine, vale la pena mencionar que esta es la única cinta que logra aparecer en el Top 20 de películas más vistas ese año (Dirección de cinematografía, 2017, p. 99). En estos casos, el personaje que se ve en la pantalla de televisión se traslada a la pantalla grande como una estrategia de mercado, apostándole a historias donde ya existe un terreno abonado desde el punto de vista de distribución, exhibición y el consumo. Debido a que los canales de televisión abierta privada (RCN y Caracol) también financian las producciones cinematográficas, tomando ventaja de los incentivos planteados por las leyes para las empresas privadas, pueden hacer uso de sus espacios de difusión para hacer promoción de estas películas. 


\section{EL APOYO DE LA LEY 814 DE 2003}

El cine es un arte donde se desarrollan ideas que luego se convierten en guiones hasta llegar al corte final (Mamet, 2008), pasando por todas los pasos o fases de la realización audiovisual (preproducción, producción y postproducción). Pero, aunque finalizada, el recorrido de una película no termina después de esos pasos. El filme debe pasar por circuitos de festivales, por la pantalla grande de los multiplex y, tras su paso por las ventanas de distribución cotidianas, a través de las televisoras nacionales, ventas internacionales e incluso hasta el VOD (Thompson \& Bordwell, 2010). El gobierno colombiano, a partir de la Ley $n^{\circ} 814$ de 2003, ha creado mecanismos para apoyar la realización cinematográfica en todas estas etapas: escritura, preproducción, producción, y postproducción de largometrajes y cortometrajes de ficción, animación, y documental. Además de apoyar la promoción a través de festivales de cine y la formación especializada para el sector cinematográfico, provee estímulos para la promoción de largometrajes en salas, así como para la participación de películas y proyectos en desarrollo en festivales, encuentros, mercados, talleres, y premios cinematográficos.

La Ley del cine (Ley $n^{\circ} 814,2003$ ) procura "afianzar el objetivo de propiciar un desarrollo progresivo, armónico y equitativo de cinematografía nacional y, en general, promover la actividad cinematográfica en Colombia," a partir de la repartición de estímulos económicos, otorgados por convocatoria pública anual y que resultan de la recolección de recursos parafiscales y donaciones administrados por el Fondo para el Desarrollo Cinematográfico (FDC).

Esta iniciativa institucional busca consolidar la industria cinematográfica en el país, "por su carácter asociado directo al patrimonio cultural de la Nación y a la formación de identidad colectiva" (Ley $n^{\circ} 814,2003$ ). Hay quienes consideran que esta ha sido una estrategia adecuada para cumplir con el objetivo planteado. Por ejemplo, el director colombiano Dago García, quien ha logrado situar películas por temporadas, tales como El Paseo (García y Trompetero, 2010) o Uno al año no hace daño, (García y Pinzón, 2015) asegura que "nunca se habían hecho [en Colombia] tan buenas películas como hoy", pero insiste en que la debilidad de la industria radica en el mercadeo (Torres, 21 de febrero de 2015). La búsqueda de nuevas formas narrativas y exploraciones temáticas del cine de la región no dialoga con el espectador de una manera tan efectiva -y rentable- como lo hace el cine más visible, respaldado por una publicidad convincente, que manipula y seduce (Valderrama, 2016), lo que ratifica la necesidad de un fortalecimiento de la industria desde la publicidad, el mercadeo que apalanque los canales de distribución y, por ende, los ingresos por taquilla.

Sin embargo, también hay quienes se han enfrentado fuertemente al sistema de estímulos, alegando que lejos de fortalecer la industria del país, la ha fragmentado y ha silenciado la realización en algunos territorios del país, pues el $66 \%$ de las películas exhibidas en el país en los diez años de operación de la Ley del Cine, fueron producciones que se realizaron sin ninguno de los estímulos. Por esto, Diana Bustamante, productora de películas como La Playa D.C. y Los Viajes del Viento, afirma que:

Uno ve en una película como Rosario Tijeras que ahí había inversión en la producción, en la promoción, algo que no conocíamos acá, un cine con billete. Los viajes del viento también era otro cine que no conocíamos, un cine de autor, pero con billete. Esos son dos extremos bien diferentes de lo que han sido estos diez años de la Ley de Cine. (Diana Bustamante, comunicación personal, 12 de marzo de 2017).

Estos dos extremos muestran una tendencia: por un lado, las obras de autor y por otro, los productos con visión comercial. Esto hace que la industria cinematográfica colombiana tenga dos visiones, una económica y otra puramente artística. Si se busca internacionalizar el cine en Colombia, es necesario enfocar la mirada a la búsqueda de mercados externos a través de cuatro líneas: a) fondos internacionales, b) coproducciones, c) ventas en el exterior, d) comisiones fílmicas (para atraer rodajes extranjeros al país) (D’Abbraccio, 2015).

Desde la aparición de los estímulos, en el año 2004 , se ha podido desarrollar proyectos de diversa índole, temáticas, géneros, y visiones. Esto ha generado un sentido de industria incipiente tras el paso de Focine, que existió entre 1978 y 1993, permitiendo el desarrollo de películas que tuvieron cierta relevancia en circuitos de festivales europeos, como Crónica de una muerte anunciada (Gasser, von Buren, López y Rosi, 1987), La Estrategia del Caracol (Cabrera, Cabrera, Nieto y Silvestri, 1993), Cóndores no entierran todos los días (Norden, 1984), entre otros títulos. Estas raíces sembradas generaron una incipiente profesionalización de cargos dentro de la industria, entre los que se cuentan: productores, directores de fotografía, directores de arte, luminotécnicos, o camarógrafos. 
En los 13 años de ejecución de la política pública desde la Ley $n^{\circ} 814$ (2003) se ha invertido un total de 213.815 millones de pesos, o 94,06 millones de dólares. La tendencia de inversión se ha mantenido al alza, con pequeñas fluctuaciones a lo largo de los años y el monto de inversión más alta en 2017, con 30.971 millones de pesos. Sin embargo, si se miran los equivalentes en dólares, la inversión ha sido un poco más fluctuante; con un aumento relativamente constante del 2004 al 2012, donde alcanzó el pico más alto, con una inversión total de 11,05 millones de dólares. Luego se presenta un descenso corto de 2013 a 2015 (con una inversión de 8,03 millones de dólares en 2016), para volver a repuntar a 2017, con 10,14 millones de dólares. Esta fluctuación corresponde a los movimientos naturales de la Tasa Representativa del Mercado (Proimágenes, 2017).

Este tipo de aportes y apoyos económicos del Estado se hacen necesarios si se quiere lograr un escenario de igualdad de condiciones para todos los realizadores, especialmente en países como Colombia, donde la inequidad económica y social es una realidad nacional. En este sentido, se vuelve relevante el analizar qué tipo de películas e historias están recibiendo los estímulos y, en general, si el sistema está logrando los objetivos que se ha planteado. Entre el 2003 y el 2013, 79 largometrajes recibieron estímulos para su realización, gracias a los cuales el país pasó de un promedio de cuatro a 12 cintas cada año (Montoya, 4 de octubre de 2013), lo que corresponde al $55.6 \%$ de total de películas producidas en el país (Proimágenes, 2017). En 2016, el FDC entregó un total de 279 estímulos, de los cuales 46 se destinaron a aspectos de producción de largometrajes y de estos, 20 se destinaron a desarrollos de guion (Dirección de cinematografía, 2017, p. 66).

El punto de partida para abordar esta problemática es la identificación de casos exitosos y casos fallidos desde el desarrollo del FDC, en la modalidad de estímulos de producción de largometrajes. Es decir, películas que hayan sido producidas gracias al estímulo y que hayan logrado destacarse, bien sea desde sus cifras de taquiIla, o por su calidad como pieza audiovisual validada por la crítica o el reconocimiento en festivales; así como aquellas que hayan pasado sin pena ni gloria por las pantallas locales e internacionales. Todo ello teniendo en cuenta que dentro de los aspectos evaluados por jurados conocedores del tema se buscaba reconocer la visión, el tratamiento, la producción y todo el músculo que convierte una idea en papel a imágenes reproducidas a través del proyector.
Pero ¿dónde queda el espacio para las otras historias? Ese espacio se ha venido consolidando gracias a autores quiénes, a través de productoras independientes, generan una producción mixta, por llamarla de algún modo. Este modelo de producción, donde productoras independientes participan en los estímulos generados por el Estado, ha abonado el terreno para que se generen propuestas fílmicas que han tenido impacto en circuitos de festivales; ejemplos de estos casos son El Abrazo de la Serpiente (Bravo, Céspedes, Mentasti, Mentasti, Gallego y Guerra, 2016) y La Tierra y la Sombra (Bustamante, Forero, Pérez y Acevedo, 2015). Ambos casos fueron ganadores de estímulos de producción promovidos por el FDC en los años 2010 y 2012, respectivamente.

Durante el desarrollo de largometrajes, como decía Robert Wise, una película debe tener las 3 Ps -pasión, paciencia, y perseverancia- cualidades necesarias para un director de cine. Estos elementos son la fórmula con la que tal vez estos realizadores han logrado llegar a espacios que se pensaban inimaginables para muchos directores nacionales. En contraposición a estos logros alcanzados, las cifras evidencian que esas películas reconocidas por su calidad y sus historias no fueron las más exitosas en las taquillas. Tras su paso en salas, El Coco (García, Toro, Boshell y Pinzón, 2016) ha sido la película más taquillera en la historia del cine colombiano, con 1.154.386 espectadores, frente a los 450.881 de El Abrazo de la Serpiente (Bravo, Céspedes, Mentasti, Mentasti, Gallego y Guerra, 2016), según cifras reportadas por el Ministerio de Cultura (2016). Por su parte, Uno al año no hace daño 2 (García y Pinzón, 2015) reportó en 2015 un total de 548.382 espectadores, frente a los 54.583 de La Tierra y La Sombra (Bustamante, Forero, Pérez y Azevedo, 2015) (Dirección de cinematografía, 2015, p. 44). Estas cifras demuestran que, en Colombia, aquellas películas que tienen reconocimiento en festivales no son necesariamente recompensadas en la taquilla.

Es por esto que para analizar la efectividad de la política pública como método para fortalecer la industria cinematográfica en Colombia, desde la mirada de la economía política, es necesario evaluar, no solo las cifras de taquilla, sino también los procesos de producción, el desarrollo del músculo laboral, y los cargos especializados en torno a los diversos oficios involucrados; los procesos de distribución; los mecanismos de promoción; y, por supuesto, las aspectos propios del filme -el producto final- 
como elemento audiovisual, pieza artística, y producto cargado de significados.

\section{LO BUENO, LO MALO Y LO FEO DE LA LEY 1556}

El caso de la imagen de Colombia exhibida por películas extranjeras ha sido un amplio tema del debate académico y mediático muy pasional en el país. Se ha planteado que en las películas de Estados Unidos en los que Colombia es el tema, "Io que ha ocurrido por lo menos en 18 ocasiones en los últimos 30 años [es que estas películas] han sido rodadas todas en terceros países, desde México, Ecuador y Puerto Rico, hasta Estados Unidos y las Filipinas" (Becerra, 2013, p. 7). Esta imagen, que resulta problematica en términos de nuestra representación más allá de nuestras fronteras, parece ser irrelevante en el caso de Narcos, la serie de Netflix que resultó beneficiada por la Ley $n^{\circ} 1.556$ (2012) aunque exhibiese la que es, quizás, nuestra faceta histórica más problemática en términos de imagen internacional

La Ley $n^{\circ} 1.556$ (2012) ofrece beneficios económicos en términos de descuentos de impuestos o reembolsos a los costos de producción (de hasta el $40 \%$ ) o de hotelería y desplazamiento (hasta del 20\%) para aquellas producciones extranjeras que deseen utilizar el territorio nacional como locación. De ese modo, esta ley estaría "promoviendo el territorio nacional como elemento del patrimonio cultural para la filmación de audiovisuales y a través de estos, la actividad turística y la promoción de la imagen del país" (Ley $\left.n^{a} 1556,2012\right)$, esto último más desde la perspectiva de que se convierta en un lugar válido de producción internacional que no en cuanto a la imagen representada en ella. En el caso de Narcos, por ejemplo, se puede dudar del efecto positivo de representación del país y en el caso de la película Mile 22 (Berg, Levinson \& Whalberg, 2018), en la cual el escenario de la ciudad de Bogotá se usó para representar una ciudad asiática ficticia, es difícil comprender cómo esto puede servir para mejorar la imagen del país.

Siempre que se ha hablado del éxito de la Ley 1556 se hace referencia a beneficios económicos directos. Una presentación del Ministerio de Cultura (MinCultura, 2016) anuncia que el país ha recibido "tres dólares de inversión extranjera por cada dólar aportado por el estado," y se ufana con la cifra de empleos generados o la ocupación hotelera durante la vigencia de la Ley $n^{a} 1556$ (2012). No se habla de bene- ficios culturales o de capacitación de los trabajadores locales. Tampoco se habla de las formas de contratación -usualmente problemáticas en esta industria- ni de las condiciones laborales del equipo colombiano que participa en estas producciones, algo que, basados en experiencias similares de otros lugares del mundo, tiende a ser el problema de esta maquila cinematográfica (ver Miller, 2005; Curtin \& Sanson, 2017, p. 136). Fuera de esto, están los temores de sostenibilidad del modelo de service audiovisual una vez se vayan estos beneficios, y las oportunidades laborales para aquellos que han estado involucrados en estos proyectos. El beneficio, entonces, se limita al interés económico, desplazando cualquier valor de desarrollo cultural.

La estrategia de captura de las Runaway Productions -esas producciones que deciden rodar en otras locaciones para obtener beneficios tributarios o disminuir costos de producciónredunda usualmente en una disminución de las posibilidades laborales en su lugar de origen y un aprovechamiento de la precarización laboral en el lugar de destino (Miller, 2005; Curtin \& Sanson, 2016; Sanson, 2018). Aunque este fenómeno apenas se está evaluando con respecto a la Ley $n^{\circ} 1556$ (2012) en Colombia, no cabe duda de que puede estar generando ese problema ya que se inscribe bajo el mismo modelo. Ese es el lugar en donde encontramos un nuevo desarrollo, que promete nuevos fondos y una nueva centralidad al cine. Eso parece, al menos por ahora.

\section{ECONOMÍA NARANJA Y DUQUE}

En la coyuntura actual colombiana, el presidente electo en 2018, Iván Duque Márquez, una invención/criatura política del ultra-derechista expresidente Álvaro Uribe, pasó mucho tiempo como empleado del Banco Interamericano de Desarrollo. Durante su tiempo en ese puesto, llegó a ser un discípulo ferviente de una exportación conceptual inglesa al mundo, la fantasía de una economía creativa -un mundo pos-industrial, pos-contaminación- en donde las industrias culturales/industrias de copyright, eran la realidad de las naciones desarrolladas (el Norte Global) y el futuro deseado para el Sur Global. Era jefe de la División de Cultura, Creatividad y Solidaridad del Banco.

Duque es co-autor del libro del Banco, Economía naranja: Una oportunidad infinita (Buitrago y Duque, 2013). Toby recuerda, con un 
retortijón de estómago, su experiencia en un congreso peruano cuando Felipe Buitrago, coautor de Duque en ese libro, presentó las promesas extravagantes, copiadas del modelo del British Council; una religión secular que ofrece trascendencia aquí y ahora, a través de un mundo bendecido para los trabajadores, consumidores, y residentes, donde los residuos son códigos en lugar de carbono. Otros participantes del congreso intentaron fomentar una discusión sobre el tema, pero fue casi imposible. Estuvimos en la presencia de un creyente, un devoto convencido para quien las dudas no podían ser toleradas. Este libro no hace muchas referencias al cine en términos culturales, y aquellas que tiene se concentran en dinero, negocios privados, y éxito monetario y de exportación (Buitrago y Duque, 2013). No hay nada sobre el rol histórico, actual, o ideal del Estado, en relación al cine como cultura.

Pero el nuevo gobierno colombiano ya está enfatizando el valor economía de este sector, y utilizando la retórica falsa que es norma -incluyendo áreas sin enlaces orgánicos, usando estadísticas valiosas de áreas como software, con la cubierta del glamour del cine-en una pantalla extranjera:

La economía naranja está en camino de convertirse en uno de los principales motores económicos de Colombia: el mundo de la iniciativa empresarial, la tecnología y las industrias creativas ya representa casi el 3\% del PIB del país latinoamericano, lo que representa tres veces la contribución del café y casi 1,5 veces el aporte de la minería. Colombia quiere posicionarse como símbolo naranja, color de la cultura y creatividad [...] Impulsar la economía naranja es una de las prioridades del gobierno. En ProColombia, hemos identificado grandes oportunidades de ventas en el desarrollo de software, películas, televisión, animación y videojuegos. Estos son sectores que han crecido más de un $30 \%$ en exportaciones [explica Flavia Santoro, presidenta de ProColombia, la entidad del Gobierno que promueve las inversiones, las exportaciones, el turismo y la marca país en el exterior] [...] Colombia se está convirtiendo en un lugar ideal para filmar industrias como Hollywood. Antonio Banderas, Tom Cruise, Will Smith o Mark Wahlberg son algunos de los actores de talla internacional que en los últimos años han filmado películas en territorio colombiano. (Orange Economy, 15 de octubre de 2018).

En la realidad actual, tenemos un presidente colombiano para quien la cultura es mucho más que una cuestión de herencia inalienable, producción artesanal, resistencia al racismo, sexismo, o nacionalismo -son migajas en una panadería corporativa-. La cultura es un producto más, como un coche de lujo o una rodilla artificial. Es un ítem de consumo, un objeto más en el sistema llamado 'mágico' de la operación de la oferta y demanda. En el caso del cine, ya es industria y arte, a causa del costo y la organización necesaria para crear y distribuir un largometraje. Aún hay otro contexto: como presidente, Duque necesitará confrontar el contexto legal del imperialismo cultural -el copyright-. la International Intellectual Property Alliance, un frente para industrias culturales totalmente de los Estados Unidos, se queja fácilmente de Colombia:

En virtud del Acuerdo de Promoción Comercial entre los Estados Unidos y Colombia (TPA), que las partes firmaron en 2012, Colombia disfruta de acceso sin restricciones al mercado de los Estados Unidos a cambio de, entre otras cosas, la implementación de una ley de derechos de autor y un régimen de cumplimiento de conformidad con los estándares globales. Sin embargo, a partir de ahora, Colombia no ha implementado numerosas obligaciones de derechos de propiedad intelectual (DPI) en virtud de la TPA, aunque se han superado todos los plazos de transición para las obligaciones de la TPA de Colombia. (IIPA, 2018).

También sentencia que "la piratería en línea en Colombia es un problema creciente que no ha sido abordado por el gobierno colombiano y amenaza con socavar el desarrollo de la distribución legítima en línea de contenido de medios." Argumenta que en "2017, los 180 sitios web principales de piratería audiovisual en español recibieron 525 millones de visitas de Colombia." Finalmente, la Alianza está muy alterada por la Ley "Pepe Sanchez" (Ley 1835, 2017), que "crea un nuevo derecho de remuneración para directores, guionistas, compositores y otros creadores involucrados en la producción de obras audiovisuales." Se opone a esta legislación, argumentando que "[l]os derechos de remuneración obligatorios interfieren innecesariamente con los acuerdos negociados que ya generan una remuneración a las partes creativas."

\section{CONCLUSIONES}

El incremento de la producción nacional y extranjera ha sido indudable en el siglo XXI en Colombia. La incidencia directa de la política cultural en este incremento es clara y, además, es evidencia objetiva de su efectividad. Sin embargo, luego de este primer acercamiento a la industria cinematográfica colombiana se puede identificar una latente necesidad de ahondar en su estudio académico y establecer una medición objetiva de las Leyes del cine, 
como política pública que se plantea el fortalecimiento de la industria y de la cultura en el país. Dicha evaluación, debe incluir en primera medida un estudio de efectividad de los proyectos merecedores del estímulo, frente a la medición de su calidad -a partir de reconocimientos de crítica especializada y festivales- y de su sostenibilidad, frente a las cifras de ingresos por taquilla y asistencia a salas. También requiere un estudio del desarrollo de las condiciones laborales en la industria del cine colombiano, para asegurarnos que los servicios audiovisuales no se conviertan en formas de precarización laboral en el país o fuera de este.

El paso de una política centrada en el valor cultural del cine y su importancia para la construcción de nación, como lo es la Ley $n^{\circ} 814$ (2003), entra en oposición a la más reciente Ley $n^{\mathrm{a}} 1.556$ (2012), que ve en la producción audiovisual un medio de promoción turístico y empresarial, y que busca sacar provecho de las ventajas de la inversión extranjera, y de las Runaway Productions. Las dos leyes parecen evidenciar el giro discursivo entre las industrias culturales y las industrias creativas. Estas últimas encajan en el trasnochado discurso del nuevo gobierno colombiano liderado por Duque. Algunos investígadores no encuentran la más mínima evidencia de que estos subsidios se paguen por sí mismos en términos de gastos del sector privado durante la producción, o el establecimiento de infraestructuras locales de cine en curso. Las evaluaciones económicas y sociológicas de ese tipo de incentivos entre 1998 y 2013 sugieren que los créditos fiscales transferibles tuvieron un impacto irrisorio en el empleo cinematográfico y ninguno en los salarios, los créditos fiscales reembolsables no ofrecían beneficios en términos de empleo y eran solo contingentes para salarios, y ningún programa tuvo efectos claramente positivos en el empleo de los medios locales o en la economía en general (Thom, 2018; O’Brien \& Lane, 2018). Esa evidencia apoya el escepticismo acerca de los beneficios en comparación con los costos de las exenciones fiscales para las películas, en lugar de otras formas de creación de empleos de mayor duración que no tienen efectos adversos en las cuentas del gobierno. Llama la atención el riesgo de que los realizadores de cine, que podrían haber llegado a lugares particulares de cualquier manera, disfruten de ganancias imprevistas a expensas de los ciudadanos. En ese sentido, la economía neoclásica y la economía política radical pueden ponerse de acuerdo sobre la importancia de descubrir y problematizar los subsidios estatales para el capital de SoCal
(Miller, 2005; Mayer \& Goldman, 2010; Grantham, 2011).

Dentro de la esfera política, las circunstancias de legislación entorno al cine, se encuentra en una constante puja dentro del punto de vista cultural, político, y económico, en la autodefinición de nación (Hjort \& Mackenzie, 2005). Es necesario el desafío de la homogenización de los mitos y los discursos del cinema nacional (Crofts, 1993), en este caso el cine colombiano, donde ciertos géneros se han visto rezagados ante la constante de historias llenas de violencia, sexo, y drogas. Es importante profundizar sobre las historias que se están contando, desde qué lugares del territorio nacional se están produciendo, qué directores han logrado conseguir los estímulos y cuáles son las propuestas estéticas y narrativas que proponen. Hay que analizar aspectos formales como los géneros que han tenido mayor aceptación dentro del estímulo, la variación de sus propuestas narrativas y los casos de éxito y fracaso, mediante una valoración integral que contemple recaudación en taquilla, valoración de la crítica, recorrido en festivales, promoción y distribución.

Se puede afirmar que el país ha expandido su mercado fílmico, aumentado su producción y creado nuevas posibilidades de producción y consumo. Sin embargo, aún hay tareas pendientes acerca de la baja tasa de asistencia a salas de cine que exhiben productos nacionales, la desconexión de los públicos con las historias de gran parte del cine nacional, así como los desarrollos en condiciones laborales en la industria audiovisual local, y su sostenibilidad después de la bonanza artificial de los beneficios y exenciones tributarias. Esto además enmarcado en el cambio tecnológico, político y conceptual que implican los nuevos espacios de distribución tipo VOD que nos obligan a replantear lo que entendemos como producto cinematográfico.

Una clave del éxito hollywoodense se explica por su capacidad, a lo largo de décadas, de utilizar las políticas culturales de otros países para su propio beneficio. Las producciones hollywoodienses aprovechan a su favor la disponibilidad de fondos que fueron creados originalmente para estimular la industria cinematográfica local y contrarrestar la hegemonía de Hollywood. ¿Cómo lo hacen? Los grandes estudios se involucran en coproducciones locales, utilizando el talento y recursos de estos países para acceder a lo que en la profesión se suele llamar 'free money'. Este es uno de los riesgos latentes para Colombia, que la industria creativa termine 
como un espejismo de capitales migrantes. Las películas internacionales vuelvan a huir a mejores climas económicos y la primera Ley del cine y su interés de proveer una expresión de nación diferente quede totalmente desdibujada.

\section{NOTAS}

1 “El cine colombiano está atrapado en tan poderosas marejadas globales que la "nación" ya no puede operar como repositorio para un conjunto de valores culturales protectores y, bien sea desaparece como el significante privilegiado de un "cine nacional" putativo, o se presenta como poco más que una artimaña promulgada por los depredadores locales, que son clientes de sistemas globales de extracción de riqueza." (Kantaris, 2017).

2 La industria cinematográfica hace referencia al sistema interconectado que conlleva la relación entre una pieza cinematográfica, compañías productoras, estudios, distribuidores, exhibidores, actores, festivales, además de todo el equipo técnico y humano que conlleva el universo cinematográfico (Wasko, 2014).

\section{REFERENCIAS BIBLIOGRÁFICAS}

- Acosta, C., Amaya, J., Alzate, C., Jaramillo, J. y Zambrano, J. (2003). Medios y nación. Historia de los medios de comunicación en Colombia. Bogotá: Aguilar.

- Arango, J.A. (Director). Bustamante, D. y Botero, J.A. (Productores). (2012). La Playa D.C. [cinta cinematográfica]. Colombia, Brasil, Francia: Séptima Films/ Burning Blue/ Ciné-Sud Promotions/ Bananeira Filmes.

- Becerra, S. (2013). Introducción. Ver y ser vistos. Notas introductorias sobre cine, diáspora y geoestética. Cuadernos de cine colombiano, 18, 3-14.

- Benshoff, H. (2015). Film and television analysis: An introduction to methods, theories, and approaches. New York: Routledge.

- Berg, P., Levinson, S., Wahlberg, M. (Productores) \& Berg, P. (Director), (2018). Mile 22 [cinta cinematográfica] Estados Unidos: STX Entertainment /Huayi Brothers Pictures/Closets to the Hole Productions/Film 44/ The Hideaway Entertainment.

- Brancato, Ch., Bernard, C., Miro, D. y Padilha J. (Productores). (2014). Narcos [serie de televisión]. Colombia: Dynamo Producciones/Gaumont International Television/Netflix.

- Bravo, R., Céspedes, M., Mentasti, E., Mentasti, H., Gallego, C. (Productores) y Guerra, C. (Director). (2015). El Abrazo de la Serpiente [cinta cinematográfica]. Colombia, Venezuela, Argentina: Buffalo Filmes/Buffalo Producciones/ MC Producciones/Nortesur Producciones.
- Buitrago, F. y Duque, I. (2013). Economía naranja: Una oportunidad infinita Washington, D.C: Banco Interamericano de Desarrollo. Recuperado de: https://publications.iadb.org/bitstream/handle/1 1319/3659/La\%20 economia\%20naranja\%3A\%20 Una $\% 20$ oportunidad\%20infinita.pdf?sequence $=4$.

- Bustamante, D., Forero, F., Pérez, P.A. (Productores) y Acevedo, C.A. (Director), (2015). La Tierra y la Sombra [cinta cinematográfica]. Colombia, Francia, Holanda, Chile, Brasil: Burning Blue/ Ciné-Sud Promotions/ Preta Pôrté Filmes/ Topkapi Films.

- Bustamante, D. (Productora) y Guerra, C. (Director). (2009). Los Viajes del Viento [cinta cinematográfica]. Colombia, Argentina, República Checa: RCN/ Ciudad Lunar/CinemArt.

- Cabrera, S., Cabrera, M., Nieto, J.M., Silvestri, S. (Productores) y Cabrera, S. (Director). (1993). La Estrategia del Caracol [cinta cinematográfica]. Colombia: Caracol Televisión/CPA/ Crear Tv/Emme/ FOCINE/ Fotogramas S.A.

- Carrillo, J., García, D. (Productores) y Trompetero, H. (Director). (2007). Muertos de Susto [cinta cinematográfica]. Colombia: Dago García Producciones/ Caracol Televisión.

- Crofts, S. (1993). Reconceptualising national cinema. Quarterly Review of Film and Video, 14 (3), 49-67. DOI: 10.1080/10509209309361406.

- Curtin, M. \& Sanson, K. (2016). Precarious creativity: Global media, local labor. En Curtin, M. y Sanson, K. (Coords.), Precarious creativity. 1-18. Berkeley: University of California Press.

- Curtin, M., \& Sanson, K. (2017). Global machine. En Curtin, M. y Sanson, K. (Coords.). Voices of labor. (pp. 136-39). Berkeley: University of California Press.

- D’Abbraccio, G. (2015). La industria del cine Colombia. Entre el optimismo ingénuo y el pesimismo crónico. Revista Luciérnaga/ Comunicación, 7(14), 36-45.

- Departamento Administrativo Nacional de Estadística (DANE), y Observatorio Cultura y Economía. (2017). Cuenta satélite de cultura, Colombia. Resultados económicos de la cultura: Años 2015 y 2016. Bogotá.

- Dinero. (9 de septiembre de 2015). 'Colombia Magia Salvaje': una exitosa película y estrategia de mercadeo. Revista Dinero. Recuperado de: http://www.dinero.com/edicionimpresa/negocios/articulo/colombia-magiasalvaje-convirtio-exitosa-estrategiamercadeo/213558.

- Dirección de Cinematografía. (2015). Anuario estadístico del cine Colombiano 2015. Bogotá: MinCultura. 
- Dirección de Cinematografía. (2017). Anuario estadístico del cine colombiano 2016. Recuperado de:

http://www.mincultura.gov.co/areas/cinematogra fia/estadisticas-del-

sector/Documents/Anuario2016.pdf.

- Echeverri, C. I. (2014). Current financing mechanisms available in Colombia for the production of audiovisual content. En Solot, S. (coord.). Current mechanisms for financing audiovisual content in Latin America 2. (pp.77-87). Rio de Janeiro: LATC.

- Flew, T. \& Waisbord, S. (2015). The ongoing significance of national media systems in the context of media globalization. Media, Culture $y$ Society, 37, (4), pp. 620-36.DOI: $10.1177 / 0163443714566903$.

- Forero, F. (Productor) y Slee, M. (Director). (2015). Colombia mágia salvaje [cinta cinematográfica] Colombia: Off The Fence/ Grupo Éxito/ Ecoplanet.

- García, L. F. (Productora) y Castellanos, R. (Director). (2017). Operación Piroberta [cinta cinematográfica]. Colombia: Ocho y Medio Comunicaciones.

- García, D. (Productor) y Pinzón, J.C. (Director). (2014). Uno al año no hace daño [cinta cinematográfica] Colombia: Dago García Producciones/Caracol Televisión.

- García, D. (Productor) y Pinzón, J.C. (Director). (2015). Uno al año no hace daño 2 [cinta cinematográfica]. Colombia: Dago García Producciones/ Caracol Televisión.

- García, I., Toro, A., Boshell, F. (Productores) y Pinzón, J.C. (Director). (2016). El Coco [cinta cinematográfica]. Colombia: Caracol Televisión/Dago García Producciones.

- García, I. (Productor) y Trompetero, H. (Director). (2010). El Paseo [cinta cinematográfica]. Colombia: Dago Garcia Producciones/Caracol Televisión.

- Gasser, Y., von Buren, F., López, F. (Productores) y Rosi, F. (Director). (1987). Crónica de una muerte anunciada [cinta cinematográfica] Colombia, Italia, Francia: Italmedia Films/Les Filmes Arianne/Soprofilmes.

- Grantham, B. (5 de mayo de 2011). Cultural studies. Recuperado de:

http://culturalstudies.podbean.com/2011/05/15/ a-conversation-with-bill-grantham-on-hollywoodand-the-law/.

- Hesmondhalgh, D. (2013). The cultural industries (3e ed.). London: Sage.

- Hjort, M., y Mackenzie, S. (coords.). (2005). Cinema and nation. New York: Routledge.

- International Intellectual Property Alliance. (2018). Colombia: International Intellectual
Property Alliance (IIPA) 2018 special 301 report on copyright protection and enforcement. (pp. 120124).

- Kantaris, G. (2017). From postmodernity to postidentity: Latin American film after the great divide. En Delgado, M. M., Hart, S. M., y Johnson, R. (coords.). A companion to Latin American cinema. (pp. 150-66). Malden: Wiley Blackwell.

- Ley no 1.835. Ley Pepe Sánchez. Diario oficial no 50.259. El Congreso de Colombia, Bogotá, 9 de junio de 2017. Recuperado de: http://www.suinjuriscol.gov.co/viewDocument.asp?id=30031893

- Ley n 1.556 . Segunda ley del Cine, Location Colombia. Diario oficial no 48.486. El Congreso de Colombia. Bogotá, 9 de julio de 2012. Recuperado de:

http://www.cancilleria.gov.co/sites/default/files/t ramites_servicios/visas/archivos/ley_1556_de_201 2.pdf.

- Ley no 814. Primera ley del Cine. Diario oficial n 45.237. El Congreso de Colombia, Bogotá, 3 de julio de 2003. Recuperado de:

http://www.alcaldiabogota.gov.co/sisjur/normas/ Norma1.jsp?i=4449\#.

- Ley no 9. Diario oficial no 25.051. Órgano Ejecutivo, Bogotá, 8 de septiembre de 1942. Recuperado de: http://www.suinjuriscol.gov.co/clp/contenidos.dll/Leyes/1564366 ?fn=document-frame.htm $\$ \mathrm{f}=$ templates $\$ 3.0$.

- Mamet, D. (2008). Bambi vs Godzilla. New York: Focal Press.

- Martínez, G. (2008). Cinema law in Latin America: Brazil, Peru and Colombia. Jump Cut: A Review of Contemporary Media, 50. Recuperado de: http://www.ejumpcut.org/archive/jc50.2008/LAfi ImLaw/index.html.

- Mayer, V. \& Goldman, T. (2010). Hollywood handouts: Tax credits in the age of economic crisis. Jump Cut: A Review of Contemporary Media, 52. Recuperado de: http://www.ejumpcut.org/archive/jc52.2010/may erTax/.

- Metz, C. (1990). Film language: A semiotics of the cinema. Chicago: University of Chicago Press.

- Miller, T. (2018). El trabajo cultural. Barcelona: Editorial Gedisa.

- Miller, T. (2005). Hollywood, cultural policy citadel. En Wayne, M. (coord.). Understanding film: Marxist perspectives. (pp.182-193). London: Pluto Press.

- Miller, T., Govil, N., McMurria, J., Maxwell, R. \& Wang, T. (2005). Global Hollywood 2. London: BFI.

- Miller, T. y Yúdice, G. (2004). Política cultural. Barcelona: Editorial Gedisa. 
- MinCultura. (2016). Ley Filmación Colombia ha generado ingresos al país por más de $\$ 86$ mil millones. Recuperado de

http://www.mincultura.gov.co/prensa/noticias/P aginas/Ley-Filmación-Colombia--ha-generadoingresos-al-país-por-más-de-86-mil-millones.aspx.

- Ministerio de Cultura. (2016). Reporte anual de la industria cinematográfica. Bogotá: Ministerio de Cultura.

- Ministerio de Cultura. (2015). Cartilla de historia del cine colombiano. Bogotá: Ministerio de Cultura.

- Montoya, J. (4 de octubre de 2013). A 10 años de la Ley de Cine. El Colombiano.

- Moran, A. (coord.). (1996). Film policy: International, national and regional perspectives. New York: Routledge.

- Norden, F. (Productor y Director). (1984). Cóndores no entierran todos los días [cinta cinematográfica]. Colombia: Procine.

- O’Brien, N. F. \& Lane, C. J. (2018). Effects of economic incentives in the American film industry: An ecological approach. Regional Studies, 52, (6), 865-875. DOI: 10.1080/00343404.2017.1360475.

- Orange Economy Already Accounts for Almost 3\% of GDP in Colombia. (15 de octubre de 2018). $P R$ Newswire. Recuperado de https://finance.yahoo.com/news/orangeeconomy-already-accounts-almost060000802.html.

- Pathé, Ch. (Productor), Zecca, F. y Nonget, L. (Directores). (1907). Vida, pasión y muerte de Nuestro Señor Jesucristo [cinta cinematográfica] Francia: Pathé-Frères.

- Proimágenes (2017). Cine en cifras. Bogotá: Ministerio de Cultura.

- Sanson, K. (2018). Stitching it all together: Service producers and the spatial dynamics of screen media labor. International Journal of Cultural Studies, 21, (4), 359-374. DOI: $10.1177 / 1367877917692900$.

- Selig, W.N. (Productor), Boggs, F. y Persons, T. (Directores). (1908). El conde de Montecristo [cinta cinematográfica] Estados Unidos: Selig Polyscope.

- Thom, M. (2018). Lights, camera, but no action? Tax and economic development lessons from state motion picture incentive programs. American Review of Public Administration, 48 (1), 3351.DOI: $10.1177 / 0275074016651958$.

- Thompson, K. \& Bordwell, D. (2010). Film history: An introduction. New York: McGraw-Hill.

- Torres, G. (21 de febrero de 2015). La mayor debilidad del cine colombiano está en que no sabe mercadear las cosas. Revista Semana.
Recuperado de:

https://www.semana.com/enfoque/articulo/lamayor-debilidad-del-cine-colombiano-esta-en-queno-sabe-mercadear-las-cosas/418632-3

- Uribe, E. (2016). El cambio mediático de la televisión: Netflix y la televisión en teléfonos inteligentes. Palabra Clave, 19 (2), 358-64. DOI: 10.5294/pacla.2016.19.2.1.

- Valderrama, H. C. (2016). El Milagro del Cine en Colombia. Nuevo Texto Crítico, 29, 139-154. Recuperado el 6 de diciembre de 2018 en Project MUSE database. DOI: 10.1353/ntc.2016.0011.

- Villegas, E. y Alarcón, S. (2017). Historiografía del cine colombiano 1974-2015. HistoReLo, 9 (18), 344-82. DOI: 10.15446/historelo.v9n18.58785.

- Wasko, J. (coord.). (2014). The handbook of political economy of communications. New York: Wiley-Blackwell. 